\title{
Restructuring Regional Economy Based on ICT Networks
}

\author{
Makoto Hirano \\ Faculty of Regional Management, the University of Fukuchiyama, 3370, Aza-hori, Fukuchiyama-city, Kyoto Pref., 620-0886 Japan
}

Copyright $(2018$ by authors, all rights reserved. Authors agree that this article remains permanently open access under the terms of the Creative Commons Attribution License 4.0 International License

\begin{abstract}
Information and Communication Technology (ICT) gave us great influence on our society/industries as a kind of paradigm shift in many aspects. For many rural regions in advanced countries, globalization accelerated by ICT advancement caused some negative influences in industries. Manufacturing industry and agriculture in those regions were damaged and stagnated by competing with low cost products/labor-force in merging countries. The stagnation of regional economy also promoted degradation of regional commerce and unemployment that caused depopulation and aging issues in regional community. However, on the other hand, ICT advancement also brought us new potential of regional industries through virtual clustering by networking. Many small enterprises can be virtually integrated through ICT networks and can be enhanced their power by virtual integration such as real industrial clustering. By joining in such clustering, many regional enterprises regained their power. And by restructuring regional industries with those enterprises, regional economy has been recovered in some cases. This study introduces some cases of virtual clustering in industries and some regions recovering their economy by restructuring regional industries. Their manners to restructure regional economy are very suggestive for regional societies to escape from undesirable negative circulation of de-industrialization/unemployment and to realize sustainable development.
\end{abstract}

Keywords Restructuring, Regional, Economy, ICT, Networks

\section{Introduction: Background, Literature Review and Purpose of Research}

The recent rapid globalization produces not only prosperity of some parts of regions/countries but also economic disparity in many areas. By the change of the business scheme and industrial paradigm in the globalized world, many powerless enterprises/people without strong competitive competence in Japan, as well as some other advanced countries, are facing to severe survival game. The problem is that many social issues are also caused in this situation, such as depopulation, aging, and economic distress in rural regions. Those social issues also induce decrease of consumption and collapse of many retail businesses in regions. It accelerates the issues of depopulation, aging, and economic distress in rural area as a negative circulation, as schematically shown in Figure 1.

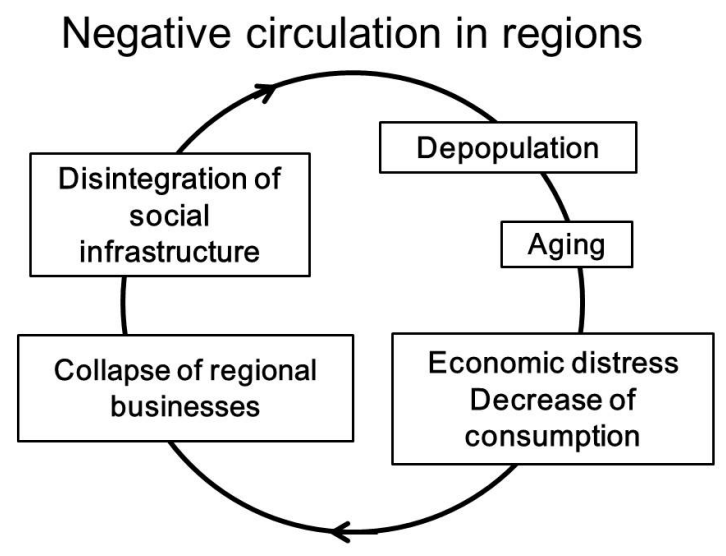

Figure 1. Reality in many rural regions through globalization

On the other hand, these issues produced serious collapse of social infrastructure, social security and even safety in rural area, in parallel to lack of public investment. In that sense, regional issues are thought as urgent national issues in Japan. This tendency is found in many industry-fields such as agriculture, manufacturing, and commerce.

1) Regarding agriculture, Japanese farms have some disadvantages in the aspect of cost issues. According to the data of year 2010 by the Ministry of Agriculture, Forestry, and Fisheries (MAFF) in Japan, the average farmland area per one farm in Japan is around 2 ha, that is almost $1 / 100$ of that in the USA ${ }^{[7]}$. In addition to that, most of the farmlands are located in mountainous areas, so that modernized 
machinery technology cannot adapt to them. As a result, because of low efficiency of production of Japanese agriculture, the competitive competency of Japanese agriculture is not strong in globalized market.

2) Regarding manufacturing, Japanese SMEs have some disadvantages in the aspect of cost issues.

According to White Paper of Small and Medium Enterprises (SME) in 2014 by the Small and Medium Enterprise Agency of Japan (METI), there are 3.853 million small and medium enterprises in Japan; that is, $99 \%$ of the total number of enterprises in Japanese industries ${ }^{[9]}$. In Japan, the definition of SME differs from industry to industry, but the term generally refers to enterprises with less than 300 employees and with a capital of less than 300 million yen. The White Paper stated that the number of SMEs has decreased over $20 \%$ within a span of 15 years from 1997 to 2012. Many Japanese SMEs have gone bankrupt or are losing the power. One of the backgrounds of recession is the shift of production-base from Japan to emerging countries in the wave of the globalization of the manufacturing industry. Many regional manufacturing SMEs without strong core-competence, in particular, are facing severe cost-competition with emerging countries. In the past, many Japanese SMEs had a strong linkage with Japanese Large Enterprises (LEs), as they were working as subcontractors for them. This strong linkage between SMEs and LEs was known as keiretsu. But in the current severe wave of global competition, many LEs have switched from contracts with domestic subcontractors to that of lower-cost subcontractors in emerging countries, because they themselves have lost their power to maintain a strong linkage with Japanese SMEs.

3) Regarding commerce, most of the conventional commercial districts in many regional cities have some disadvantages in the aspect of cost issues and convenience comparing to large shopping mall. After the deregulation of restriction of embarkation of large shopping malls by large capital enterprises in 1980's and 1990's, with the pressure for opening the domestic market by foreign governments, many regional small and medium retail shops and stores went bankrupt. According to the statistical data on commerce by METI, the number of the small and medium retail shops was decreased from around 3.4 million in 1982 to around 2.4 million in 1995 whereas the number of large retail shops with over 50 employees was increased from around 8 thousands to 16 thousands in the same periods. According to White Paper in 2015 by METI, the total floor area of the stores with over 3,000 $\mathrm{m} 2$ was increased from zero in 1976 to over one-fourth of the total in $2004^{[10]}$

By those phenomena, most of regional industries and regional economy in Japan have been stagnated and degraded in these decades, as schematically indicated in Figure 2 .

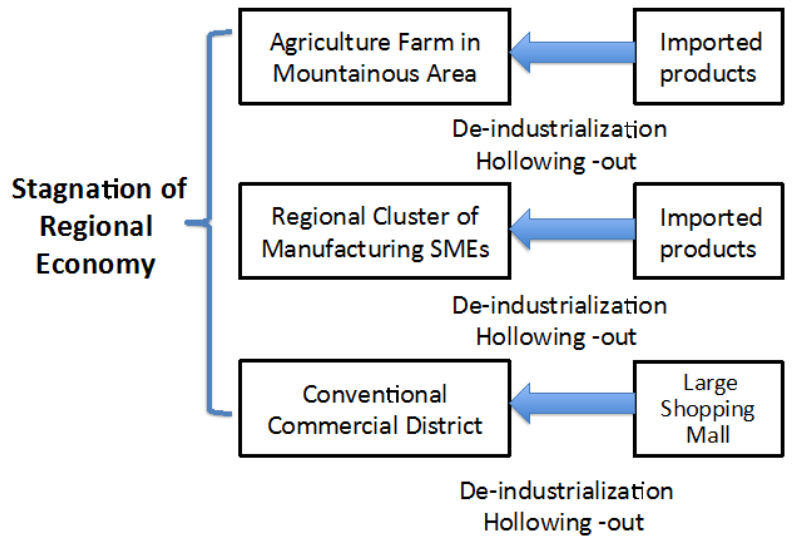

Figure 2. Regional industries stagnated trough globalization

Back to the history of economics, industrial clustering has been thought as one effective measure for many regional small and medium enterprises to enhance their power and competitive competence. Marshall (1890) pointed out the economic effect of geometrical integration of enterprises, in the viewpoints of cost reduction of distribution and scale merit on production ${ }^{[8]}$. Many researchers like Anzoff (1965) or Krugman (1980) developed the theory by focusing on synergy effect of integrated enterprises by clustering ${ }^{[1][6]}$. Based on the argument on tacit knowledge, Porter and Saxenian (1994) pointed out the synergy effect of integrated enterprises in the sense of intellectual asset and producing innovation [12][14]

Since late 1990's, proliferation and popularization of Internet enabled an enterprise to cluster with other ones through forming network in virtual space. This virtual clustering of enterprises may produce new competitive competence even for an enterprise which is geometrically isolated in remote area and have disadvantages on supply chain in conventional manner. Therefore, industrial clustering through Internet network is expected to be a new measure for encouraging powerless regional SMEs (small and medium enterprises) in manufacturing, commerce and also small size local farms in the same context.

In order to obtain some implications for solving regional issues, this paper introduces some typical cases in those which ICT network plays a significant role for establishing a kind of virtual clustering and new business models in regions. The concept of industrial clustering was explained by Porter $(1990)^{[12]}$ as the mutually connected many enterprises and organizations in a specific industry with mutually enhanced power (synergy effect) through their similarity and complement and also through their competition and collaboration. Porter pointed out the advantage of physical clustering in geometrically integration at first but also pointed out the advancement of distribution system produced the new form of clustering ${ }^{[13]}$. If many small regional enterprises can be clustered through ICT networks on the platform of portal-site service on a specific industry, they can also mutually enhance their 
power such as physically integrated industrial cluster except prompt low-cost mutual distribution of products/materials. The rapid advancement of current logistics reduced the disadvantage of virtual clustering in comparison with real clustering, so that virtual clustering by ICT network is gaining their power.

The first group of cases will indicate new business models on virtual clustering utilizing ICT network, and the second group of cases will indicate reforming regional societies by virtual clustering enterprises. Both groups of cases are analyzed in the viewpoint of paradigm shift of industries, economy and society in regions. Analysis lead us additional discussion on the potentiality of utilizing ICT for encouraging powerless enterprise/people in various manners.

\section{Virtual Clustering using ICT Network in Industries}

Nowadays, purchasing items through Internet is very popular for everyone over the world. Forming portal site as a virtual mall of Internet shopping, supply side can be clustered to increase convenience of ordering by demand side, and also demand side can be clustered to increase transaction level of sales for supply side. Both sides can obtain benefit through Internet platform beyond disadvantage of physical (geometrical) location for purchasing and sales. In Japan, market size of consumer electric commerce has been rapidly grown since late 1990's. According to METI, ECOM, and NTT Data IMC joint survey on actual condition and market size of electronic commerce (e-commerce), the market size was increased from around 650 million US dollar in 1998 to around 56 billion US dollar in 2004. Also, according to the statistical data by METI (Ministry of Economy, Trade and Industry, Japan), The market size of BtoC e-commerce reached around 150 billion US dollar and BtoB e-commerce reached around 2.9 trillion US dollar in 2016. METI report also described that $\mathrm{CtoC}$ (consumer to consumer) e-commerce market in 2016 was around 3.4 billion US dollar only for online auction ${ }^{[11]}$. The appearance of e-commerce market gave great influence to many industries.

1) Regarding commerce, there is a direct impact for retail sales. Many small regional enterprises are involved in portal site business for Internet shopping or Internet auction, such as Yahoo, Rakuten, Kakaku.com, and Amazon in Japan as well as many other countries in the world. Not only for items but also for restaurants, hotels, trains, flights, and many other services, Internet is used very popularly. This is a well-known change of retail/service businesses in the current world. Although most of the regional commercial districts in many regional cities became stagnated, if some retail stores or shops have some unique competences, they could have an opportunity to survive because of the online-shopping mall services which produced virtual clustering of retail industry, apart from physical clustering in real world.

2) Regarding agriculture, there is also an impact of Internet sales after 1990's. One typical example is Oisix.daichi corporation. It was established by Kouhei Takashima in 2000, when he was late 20's. The mission of the enterprise was to realize affluent lives on food in Japan. They initiated the business to provide safe and reliable food products such as organic vegetables through Internet portal site to consumers. Their annual sales reached up to around 23 billion US dollar and ROS is around 3\% in 2017. They have around 140 thousand memberships of purchasing vegetables through their Internet platform. Their business produced the opportunity not only of purchasing agricultural products for consumers, but also of selling agricultural products for rural farms in spite of disadvantageous geometric locations. That is, the portal-site service in Internet bought an opportunity of business for farmers in rural regions. The virtual cluster of agriculture could be advanced by current distribution system.

3) Regarding manufacturing, as well as retail/service industries and agriculture, supply chain and distribution networks in what we call B2B (Business to Business) transactions are also changed by progress of ICT. The change of networks spread from B2C (business to consumers) to B2B. This caused a kind of virtual clustering of industries. Misumi group Inc. was established in 1963, as retail/trading enterprise on mechanical processing components. The current annual sales are around two hundred and sixty billion yen (circus two and a half billion US dollar) and their employee's number is over ten thousand. Their business was advanced by catalog sales, mail order, and Internet transaction (e-commerce) on small amount of components to small enterprises. Because usually transaction on components was restricted to large scale and mass consumption, the Misumi system was much convenient for many small enterprises. They established a kind of platform of virtual clustering of manufacturing SMEs (small and medium enterprises). The business model of Misumi was copied to many other fields of business. Cygni Corporation is also a mail order house and Internet service handling medical materials and items for hospitals and shops for Pet-animals. Before their appearance, each pet shop and animal hospital should purchase medical material $\mathrm{s}$ and medical items by each. Sometimes it was troublesome to find the relevant retailers and also it was difficult to 
purchase a small amount of items. However, by utilizing Cygni, they can easily find out the relevant shop and purchase small amount of materials/items. At the same time, the manufacturing SMEs on pet medical materials/items became to sell their products in long tail business, and the total sales became larger by utilizing Internet platform formed by Cygni. Another example is Tagboat Corporation. It was established in 2008, which is a kind of Internet virtual gallery selling contemporary artworks through Internet. Although artists are quite different from manufacturing enterprises, the architecture on supply-chain was changed as well as the case of Cygni or Misumi. Through these portal site businesses and mail order houses, many small manufacturing enterprises and even artists in many rural regions could obtain transaction opportunity just as virtual clustering industries. The other typical case of restructuring B2B manufacturing industry through ICT network is a case of Komatsu. The details of the case have been submitted by the author in $2010^{[3]}$. Komatsu established their portal service in Internet, which could provide a lot of information to their customers, agents, and venders. They could share the information of maintenance and exchanging components/modules through portal-site by Komatsu, and many small manufacturing vendors could behave as a kind of component manufacturing cluster.

In these cases, the paradigm shift of industries was happened and the prosperity of physically clustered enterprises was shifted to the prosperity of virtually clustered enterprises. Through this process, regional industries were restructured by Internet platform as schematically indicated in Figure 3.

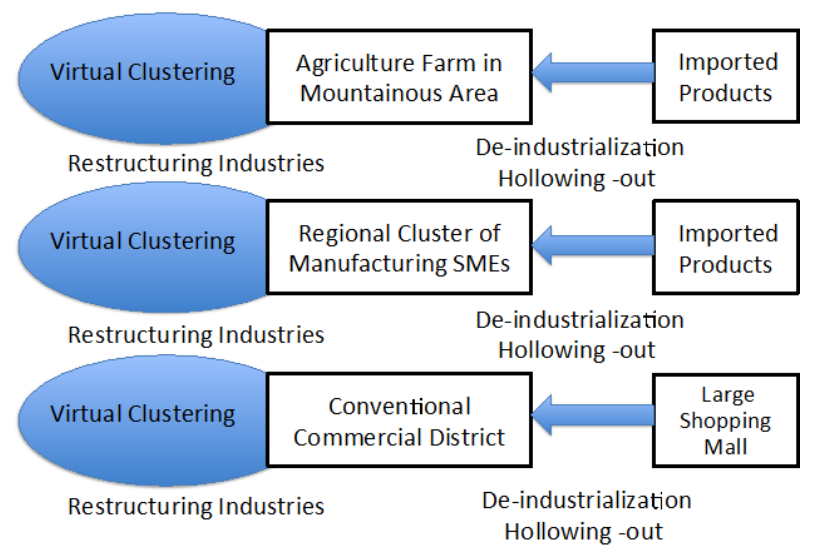

Figure 3. Restructuring industries by virtual clustering

\section{Influence to Regional Society}

The second group of cases is the cases of reforming regional economy/communities by the power of ICT network.

\section{1) Case of Kamikatsu city}

The first case is a business of selling leaves in local village by Irodori Corporation, in Kamikatsu city, Japan. (The details of the case have been submitted by the author in $2010^{[4]}$.)

The city is located in remote mountainous areas in Shikoku Island, with the population of about two thousand. Over a half of the people is senior generation over sixty-five years old. More than twenty years ago, typhoon damaged their orange agriculture that was the main industry of the village, and the village people were at a loss in losing their business resource. Mr. Yokoishi, a member of the village agriculture union (a branch of Japanese Agriculture Union), came up the idea of selling leaves in mountains to urban luxurious Japanese cuisine restaurants, at that time. Because the chefs of those restaurants are usually using natural leaves as decorations of luxurious traditional Japanese dishes, he though the village people could sell their leaves in mountains as commercial items. The first time when they initiated the business of selling leaves, most of the village people did not believe that it could be a real business to earn money. As a matter of fact, no body purchased their leaves at that time. However, Mr. Yokoishi did not give up and spent over ten years for marketing on how to make their leaves commercial items. As well as the ordinary commercial items, there were special demands of users on specifications of items. For example, users had the specific demands on features, colors, qualities, sizes, thickness of leaves, numbers of leaves with same quality as a commercial item and also a demand for delivery timing. Mr. Yokoishi had been visiting many luxurious, expensive restaurants as a customer by spending much personal money to research suitable specifications of leaves for the target restaurants. After long time effort of his personal marketing, finally he established the know-how on how to sell leaves in mountains as commercial items. And he also established relevant supply-chain-management system using broad-band-service Internet technology. By this platform system, each independent powerless farm, which consists of mainly senior persons over eighty-years-old, can get information of daily up-to-date requests on leaves from restaurants, and they can harvest fresh leaves in mountains to ship them immediately by using airline delivery service. The powerless village farms could form a kind of a virtual cluster for leaves business as a new part of agriculture.

Nowadays, the village people earn totally around three hundred million yen (equivalent to around three million US dollars) a year by selling leaves, and a certain old lady over eighty years old can earn over ten million yen a year only by selling leaves. An interesting story is that, nowadays, they can earn larger money by selling leaves of one persimmon tree than selling fruits of the same one tree. The point of this story is that they could establish business by effectively utilizing the existent natural resources and the 
existent human resources, even though both resources were not thought to be so useful. Also, their business enables to utilize powerless senior people. Usually a senior people over eighty-years-old cannot be involved in business, but in this case they can utilize their special knowledge about leaves in mountains and are vividly involved their business. They are so pleased to be involved in business and earn money by themselves that they became very healthy. The total medical care expense in the village became very small by the indirect effect of the business. Their business style is sustainable and ecological. They utilized existent resources without damaging natural environments. This case implicates a new style of innovation/business for us to survive in the limit of resources and growth of the global world. This success story became very famous even overseas, and Mr. Yokoishi was evaluated one of the most successful social entrepreneurs in the world by an American journal. In the cases of Kamikatsu-city, new business model by clustered farms in the same local city enabled them to survive in rural mountainous area.

\section{2) Case of Kamiyama city}

By restructuring regional industries/economy, restructuring regional society/community became possible by strong intention of the members of community. The case of Kamiyama-city indicates such situation ${ }^{[5]}$.

The population of Kamiyama-city is about 6000 but it has been decreased as well as ordinary rural regions in Japan. Kamiyama-city is located in mountainous area in Tokushima prefecture. They have a hot spring and tourism was one of their industries, but nowadays the tourist number has been decreased. Mr. Shinya Ominami was born in the city and spending two years in the USA as a master student of civil engineering. After coming back to his hometown to succeed the family business of construction business, he became to think about vitalization of his city. In 1997, he initiated to vitalize the city by the project of artist in residence, which he has learned in the USA. He invited three artists to the city, and let them staying for two months by free, utilizing vacant house and support of food supply by the neighbor farms. During this free staying, artists were required to make their artworks and after two months, they held an exhibition of their artworks in the city. By this event, the name of the city has been getting famous and the number of visitors has been increased. In addition to that, he produced many activities and events to encourage the city. He established Non-profit organization named Green Valley in 2004 and initiated rental house business in 2007. The purpose of the business was to rent a vacant house that the owner has been moved out to other area to the outside people to live in the city. But one important strategy of the business is they have a plan to reform the industries/society in the region intentionally. They imagined the future of the city twenty years later or thirty years later and objectively think what kind of industries can support the community. And then, they invited professional people or enterprises that are engaged in those industries very strategically. Step by step, they invited an enterprise of IT industry, a motion picture creator, a bakery selling items through online-mall, and so on. ICT advancement and virtual clustering enabled them to be engaged in their business in rural region. That is the intentional restructuring regional industries, economy and society itself. Mr. Ominami said that we cannot avoid depopulation itself so that we would like to think about creative depopulation, and one thing is that we will reform this city just as Silicon Valley in the mountainous area in Japan. The population of the city is now increasing little by little, very amazingly in Japanese reality.

Kamiyama model of restructuring regional society is schematically indicated in Figure 4. They invited enterprises/people to reform the industry structure of the city. The invited enterprises/people are clustered through Internet with outside world, so that the power of the city is enhanced by virtual clustering based on ICT network. This model of restructuring regions is suggestive for many other rural regions to survive in globalization and their sustainable development.

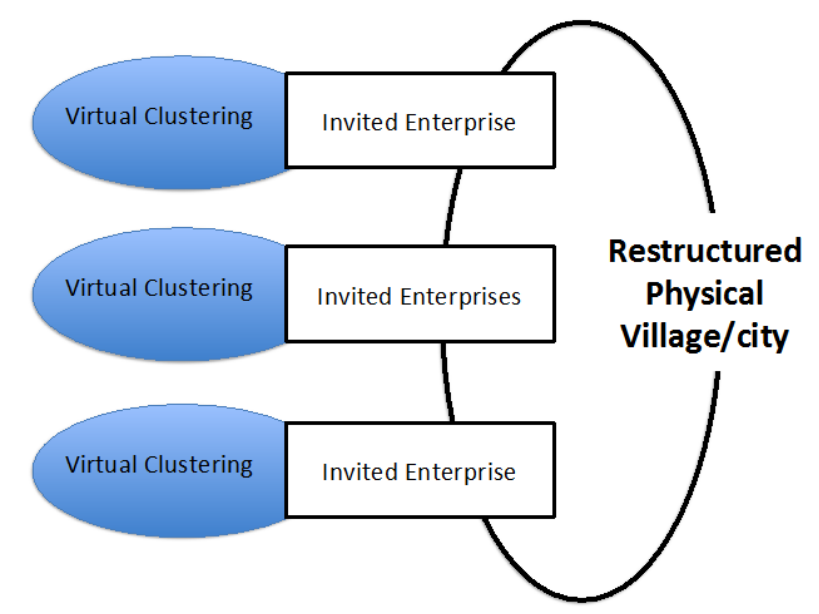

Figure 4. Physical village/city of enterprises belong to virtual clusters

\section{Discussion}

The case of Kamiyama-city is thought to be a typical example of restructuring regional society/industries. They are intending to reform the community and the industries in region by positively using ICT network and virtual clustering.

Because the idea of virtual clustering is basically encouraging conventional regional industries by only utilizing ICT network and portal-site services without any additional production or wasting materials, it is effective to develop social economy sustainably and protect natural environment of the earth, as Daly (1996) stressed the significance in his book [7]. The model of restructuring might be very suggestive not only for the other areas in 
Japan but also for many other areas in other countries.

In the cases introduced in this paper, ICT network and virtual clustering play an important role of combining a large number of powerless people/enterprises to establish and complete their business models, maintenance service of construction machines, supplying leaves as decoration for luxurious dishes, and so forth.

Today, there are many varieties of ICT networking systems to assist some other business models by powerless people. "Cloud-funding" is thought to be a kind of such systems because it assists people without capital power or economic resources to initiate their businesses by collecting small investments from ordinary consumers. Some portal sites in Internet are able to play a role in the same context. By using Internet, some consumers are assisting the businesses of manufacturing SMEs or small farms by direct and continuous purchasing their products. As another example, "Community Supported Agriculture (CSA)" is known as a system to support specific small farms by consumers. If some consumers have a will to support the business of some specific farms because of their preference on organic agriculture or some special demands for agriculture products, they can continue direct purchasing the products from them with sharing the risk of agriculture production affected by natural environment. For those kinds of business models, ICT network can operate very effectively.

Finally, it should be emphasized that in any case of establishing ICT system for people/society, much efforts for establishing human (not virtual, but real) network/linkage are also needed in parallel to the system. Because how to utilize the system effectively is essentially a human issue, in that sense, the ICT system itself is only one step for realizing virtual cluster. In the case of Komatsu, they were making much effort to communicate with local agents, vendors, related SMEs. Sometimes they are meeting physically to communicate with each other and have some training together. Based on such effort, their ICT system can operate efficiently. Also, in case of Irodori, Mr. Yokoishi established customized web portal site for village people, which can be very familiar with local farmers, and effective for deep communication including daily chatting. This kind of effort enabled them to utilize ICT system so efficiently.

Also, to realize the restructuring as indicated in Figure 4, regional community should have a power of entrepreneurship and mutual stimulation/collaboration as a kind of social capital. In such a sense, the power of social capital of region is thought to be strongly connected to the potentiality of restructuring economics of the region.

\section{Conclusions}

Many rural regions in Japan are facing social issues, such as deindustrialization, unemployment, depopulation, and aging, based on stagnation of regional economy mainly caused by globalization. ICT system/network can give us varieties of measures to cope with such social issues by encouraging regional economy.

This paper introduced some cases of utilizing ICT network. The first group of cases is a kind of virtual cluster in industries. By utilizing ICT network, many powerless enterprises could enlarge the opportunity of business, in spite of disadvantage of physical location. The second group of cases is a kind of restructuring regional society by utilizing ICT network and virtual clustering. By inviting enterprises virtually clustered with outside world, they could reform the regional economy and thus regional community for sustainable development. Also, to realize the restructuring regional economy, the introduced cases infer that social capital such as entrepreneurship or collaboration plays an important role.

Many cases introduced in this paper would be suggestive for many other stagnated regions in other countries.

\section{REFERENCES}

[1] Anzoff, H. I., Corporate Strategy, MaGraw-Hill, 1965.

[2] Daly, H. E., The Economics of Sustainable Development, Boston, MA: Bacon Press, 1996.

[3] Hirano, M., "Co-Evolving Management with Virtual Cluster---What we can learn from Komatsu's networking strategy," The 14th International Conference on Concurrent Enterprising, Lugano, Switzerland, June 2010.

[4] Hirano, M., "Sustainable Innovation in Regional Development---Implication for Ecological Style of Business Management," Regional Studies Association Symposium, Pecs, Hungary, May 2010.

[5] Hirano, M., Regional Development through Ecological Business: Unique cases in Japanese rural regions, Routledge, UK, 2013.

[6] Krugman, P., Geography and Trade, The MIT Press, 1991.

[7] MAFF (Ministry of Agriculture, Forestry, and Fisheries), White Paper, 2010

[8] Marshall, A., Principals of Economics, Macmillan, 1890.

[9] METI (Ministry of Economy, Trade and Industry, the Small and Medium Enterprise Agency), 2014 White Paper on Small and Medium Enterprises in Japan, 2015.

[10] METI (Ministry of Economy, Trade and Industry, the Small and Medium Enterprise Agency), 2015 White Paper on Small and Medium Enterprises in Japan, 2016.

[11] METI (Ministry of Economy, Trade and Industry, the Small and Medium Enterprise Agency), 2016 report on e-commerce market. URL: http://www.meti.go.jp/press/201 7/04/20170424001/20170424001.html

[12] Porter, M. E., The Competitive Advantage of nations, The Free Press, 1990. 
[13] Porter, M. E., Clusters and Competition: New Agenda for Companies, Governments and Institutions, On Competition, Harvard Business School Press, 1998.
[14] Saxenian, A., Regional Advantage: Culture and Competition in Silicon Valley and Route 128, Harvard University press, 1994. 